\title{
Identity profiles and digital engagement among Finnish high school students
}

\author{
Rasmus Mannerström¹, Lauri Hietajärvi², Joona Muotka1 , \& Katariina Salmela-Aro² \\ ${ }^{1}$ Department of Psychology, University of Jyväskylä, Jyväskylä, Finland \\ ${ }^{2}$ Department of Education, University of Helsinki, Helsinki, Finland
}

\begin{abstract}
Developing a stable personal identity is considered a more precarious task in today's society than hitherto. Skilful digital engagement may, however, constitute a valuable asset in necessary identity exploration and commitment. Applying a person-oriented approach, we examined for the first time how identity profiles are associated with digital engagement, operationalized as digital competence, gaming seriousness, type of internet activity and excessive ICT use. After controlling for gender, life satisfaction and parental SES, this study of a Finnish high school sample $(N=932)$ revealed that adolescents with future commitments and some exploration of options (achievement, searching moratorium) were the most advanced in digital skills and, in the former case, least prone to excessive ICT use. By contrast, adolescents desperately trying to solve the identity task (ruminative moratorium) scored highest on friendship-driven internet activity and excessive ICT use, whereas diffused individuals had the weakest digital competence. No differences between the profiles emerged regarding gaming and interest-driven internet activity. The results suggest that the digital world and related devices are purposeful tools for shaping and maintaining healthy identity commitments.
\end{abstract}

Keywords: Identity formation; identity status; person-oriented approach; digital engagement

\section{Introduction}

Constructing a healthy identity is currently considered a pressing research issue owing to increasingly uncertain and contingent societal circumstances (e.g., Mastrotheodoros \& Motti-Stefanidi, 2017). Simultaneously, youth come of age in a digitalized and interconnected online world that offers them unprecedented access to information, knowledge sharing and peer support. Finnish education is globally known for its equity and high quality (Niemi, 2014; Organisation for Economic Co-operation and Development [OECD], 2015). Acknowledging the demands of 21 st century societies and issues related with digital inequalities, the Finnish government and authorities have recently invested massively in digitalisation of schools, learning and improvement of students' digital skills (City of Helsinki, 2016; Ministry of Education and Culture, 2016). It remains to be seen if these tools and new opportunities will help adolescents explore their future options and make decisions, that is, to find a stable identity. In this study, we examined whether identity profiles of commitment to and exploration of future plans are linked to digital engagement among Finnish high school students.

\section{Identity Development}

Erikson $(1950 ; 1968)$ perceived identity consolidation as the core developmental task of adolescence. Identity refers to a sense of purpose and continuity which arises out of commitments to ideals, roles and future plans. Maintaining identity is essential for psychological well-being throughout life because confusion over one's future 
direction may thwart decision making in subsequent life challenges, placing further personal and social development on hold.

Empirical research on identity formation in the Eriksonian framework has largely focused on measuring the extent to which an individual has explored alternatives and made commitments in different life domains (Marcia, 1966; 1993). By crossing the two dimensions, individuals can be assigned one of four statuses indicating the outcome of identity formation. Individuals within the achievement status have already explored different options and made commitments. The moratorium status represents the transitional crisis, consisting of individuals who have not yet reached commitments but are currently exploring alternatives. In contrast, individuals who have already made commitments without prior exploration are assigned the foreclosure status. Lastly, the diffusion status consists of individuals who lack both exploration and commitments. Accumulated research has shown the statuses to be differently related to various external correlates such as personality characteristics, cognitive processes and interpersonal behaviour (Kroger \& Marcia, 2011). Most importantly, identity-achieved individuals have consistently scored highest in terms of psychological well-being, while subjects in diffusion and moratorium have the lowest scores.

Although Waterman (1982) suggested a developmental trajectory between the statuses in which adolescents progress from diffusion to either foreclosure or through moratorium to achievement, recent longitudinal studies have shown identity status development to be much more stable, non-linear and dependent on demographic variables than previously thought (Fadjukoff, 2007; Kroger, Martinussen, \& Marcia, 2010; Meeus, van de Schoot, Keijsers, \& Branje, 2012). That is, in addition to progression between the statuses over time, great stability and some regression have also been observed. Further, although gender differences have been very small or nonexistent (e.g., Kroger, 1997; Schwartz et al., 2011), other contextual factors such as prior school success, parental SES and larger economic circumstances play a significant role in the development and distribution of identity statuses (Fadjukoff, 2007; Fadjukoff, Kokko, \& Pulkkinen, 2010; Mannerström, Hautamäki, \& Leikas, 2016). For instance, adolescents with highly educated parents are more likely to reach the achievement status. Similarly, the number of diffused individuals increases during economic recessions. Taken together, achieving identity does not seem like a fixed end-target. Instead, identity appears as a continuous, context-dependent and multidirectional process that demands ceaseless reclaiming.

Current multidimensional process-models, such as that proposed by Luyckx, Goossens, Soenens, and Beyers (2006), better capture the iterative and dynamic nature of identity formation. They maintain that identity consolidation consists of two formation processes - exploring different alternatives and making commitments (i.e., exploration in breadth and commitment making) - and two evaluation processes, which involve how current commitments are reflected upon and identified with (i.e., exploration in depth and identification with commitment). Later, a fifth process, ruminative exploration, was added to the model (Luyckx et al., 2008). In contrast to the adaptive exploration processes, ruminative exploration signifies a dysfunctional type of brooding over different alternatives that interferes with commitment-making processes. Rumination is an important factor in the assessment of identity formation in current western societies because youth are increasingly prolonging exploration or avoiding commitments altogether (Arnett, 2004). It has been suggested that settling on a future direction and gaining a sense of identity are more difficult than before (Côté, 2006; Elliott, 2015). Seemingly endless but unequal and -structured life path opportunities alongside a market-driven spirit of constant re-invention and flexibility on all levels of society increase uncertainty and rumination regarding the future. Counteracting these tendencies increasingly demands the capacity of personal agency in decision-making and life path choices (Schwartz, Côté, \& Arnett, 2005).

To test their dual-cycle model (Luyckx, Goossens, \& Soenens, 2006), Luyckx and colleagues (2008) developed the Dimensions of Identity Development Scale (DIDS), commonly used within the identity domain of general future plans, but also applicable within domains such as intimate relationships and work (Luyckx, Seiffge-Krenke, Schwartz, Crocetti, \& Klimstra, 2014). The DIDS allows both a variable- and person-oriented approach (Crocetti \& Meeus, 2015). In the former case, the relations between exploration and commitment identity dimensions and some external variables are evaluated. In the latter, participants are first assigned to one of the identity statuses through cluster analyses (CA) or latent profile analyses (LPA) that combine measures of exploration and commitment, then the associations between identity statuses and external variables are evaluated. 
In a wide range of studies across different contexts, the DIDS has repeatedly produced 5-6 different clusters or groups, four similar to Marcia's original statuses (e.g., Luyckx et al., 2014; Mannerström et al., 2016; Schwartz et al., 2011; Zimmerman, Lannegrand-Willems, Safont-Mottay, \& Cannard, 2013): achievement (scoring high on all dimensions except low on ruminative exploration), foreclosure (labelled early closure by Meeus, van de Schoot, Keijsers, Schwartz, \& Branje, 2010, scoring moderately high on both commitment dimensions but low on all exploration dimensions), moratorium (scoring low on both commitment dimensions and high on all exploration dimensions), and diffusion (scoring low on all dimensions except moderate to high on ruminative exploration). New statuses identified with the DIDS include searching moratorium (moderately high scores on all dimensions, see Crocetti, Rubini, \& Meeus, 2008; Schwartz et al., 2011), carefree diffusion (scoring low on all dimensions), and undifferentiated (intermediate scores on all dimensions: Luyckx et al., 2008). Studies with the DIDS have shown that the identity statuses differ significantly on several measures of psychosocial functioning (Luyckx, Duriez, Klimstra, \& De Witte, 2010; Schwartz et al., 2011). In general, subjects in the achievement status are best adjusted, followed by those in foreclosure, searching moratorium, carefree diffusion, undifferentiated, and diffusion.

In summary, exploring and committing to future life paths yields certainty, direction and predictability, that is, a sense of identity that is fundamental for psychological well-being. Identity development does not, however, follow a normative and linear track as previously assumed; instead, it is a ceaseless process dependent on contextual factors. This has important societal implications, because actively supporting identity consolidation among youth means supporting psychological well-being, which in turn is beneficial for health and economy on a national level. In this task, digital skills, social networking and gaming may offer new means and resources for exploring and establishing identity commitments. In this paper we use the term identity profiles synonymously with statuses.

\section{Digital Engagement}

Information and communication technology (ICT), the internet and social media offer constant interaction with other people and information. Digitally mediated social interaction has given rise to new ways of living, working, communicating and learning (Curran, Fenton, \& Freedman, 2016; Schwab, 2017). We employ digital engagement as an umbrella term for the digital practices and competencies that are central to adolescents' everyday lives, considered essential for social integration in the 21 st century knowledge society, and increasingly integrated in Finnish educational institutions (Niemi, Kynäslahti, \& Vahtivuori-Hänninen, 2013). For instance, interacting with others over the web, sharing knowledge, and mastering computer programs for creating, designing or programming artefacts all help develop the digital literacy (cf. digital capital) demanded by future labour markets (Gallardo-Echenique, de Oliveira, Marqués-Molias, \& Esteve-Mon, 2015; Trilling \& Fadel, 2009).

However, digital practices and engagement are not uniform across youth but instead vary in form and magnitude. For instance, Ito et al. (2009) distinguish between friendship-driven (keeping up peer relations) and interest-driven (learning about a specific object) motivations in digital engagement. Friendship-driven activity includes social networking, entertainment and gaming, whereas interest-driven activity consists of creative, artistic and goaloriented media use ranging from searching for information to creating and sharing text, videos, websites and serious ICT expertise. Several studies show that the majority of adolescents in many western countries engage primarily in friendship-driven activities (Eynon \& Malmberg, 2011; Ito et al., 2009; Kennedy, Judd, Dalgarno, \& Waycott, 2010; van den Beemt, Akkerman, \& Simons, 2011).

Furthermore, digital engagement is bound up with structural inequalities in gender, ethnicity and social class, with adolescents from wealthier families having better access to ICT, digital competence and more interest-driven activities than their less privileged peers (Heinz, 2016; Robinson et al., 2015). Additionally, boys are more into interest-driven activities and gaming and have better ICT skills than girls. Robinson and colleagues (2015) worry that digital inequalities and related engagement produces significant micro- and macro-level outcomes, most notably different life opportunities and trajectories. The danger is that digital divides may deepen social and economic divides. Thus, current research has shifted to focus on the outcomes of different forms of digital engagement for different groups.

For instance, we currently know that social networking and gaming are associated with both positive and negative socio-psychological outcomes. In the former case, depending on game type and genre, gaming can increase prosocial behaviour and civic engagement as well as cognitive and visual-spatial skills (Anderson, 2014; Gabbiadini 
\& Greitemeyer, 2017; Green, Gorman, \& Bavelier, 2016; Greitemeyer \& Mügge, 2014). In the latter case, extensive gaming has been associated most notably with low life satisfaction and addictive behaviours (Gentile, Coyne, \& Bricolo, 2013; Manago, 2015; Prot, Anderson, Gentile, Brown, \& Swing, 2014 for reviews). Extensive gaming may push aside other enriching activities and simultaneously operate as a form of escapism, masking psychosocial problems such as low life satisfaction (Kardefelt-Winther, 2014; Przybylski, 2014).

Thus, socio-digital participation is not a passive activity. Instead, it deeply penetrates social and cognitive development (Ito et al., 2009; Manago, 2015). How we use digital tools simultaneously reflects and shapes ways of communication and learning, meaning that more demanding digital engagement reflects more complex knowledge practices (Hakkarainen, 2009). In turn, mastering digital tools and producing and sharing knowledge digitally is now commonly perceived as a critical resource for success and social integration in the 21st century knowledge society (Gallardo-Echenique et al., 2015). In other words, digital engagement profoundly mediates social life and coping skills in society, giving it a meaningful role in adolescent development (Ito et al., 2009; Manago, 2015; Przybylski \& Weinstein, 2017).

\section{Identity Development and Digital Engagement}

Given that digital technology influences how we develop socially and cognitively, it provides new opportunities for and challenges to identity consolidation. For instance, the immense informational resources of social media, gaming and networking sites offer peer support and a sense of belonging, and they expand possibilities for exploring, reflecting and deciding upon different education and career alternatives (Manago, 2015). Similarly, customizing a social world representing one's circumstances and interests requires individual agency and responsibility for self-image, which may promote self-concept clarity (Gonzales \& Hancock, 2008; Manago, 2015). Besides being a sounding board of self-reflection, digital engagement develops competence (cf. digital literacy) that in itself offers career paths in the 21st century working environments (Gallardo-Echenique et al., 2015; Trilling \& Fadel, 2009). In our view, mastering skills such as online communication, knowledge sharing, programming and media creation offer career opportunities that dynamically influence self-image, personal preferences and choices of future direction. In this way, digital tools and the socio-digital world shape and enhance our capacities and may reinforce identity exploration and consolidation.

On the other hand, social networking also demands strategic self-presentation, which may lead to cognitive overload (Gentile, Twenge, Freeman, \& Campbell, 2012; Misra \& Stokols, 2012). A preoccupation with attractiveness leads to social evaluation, shallow relations with others and a dissatisfied attitude towards the self, delimiting autonomy and undermining identity (e.g., Haferkamp \& Krämer, 2011). Similarly, gaming can interfere with identity development by becoming a substitute for real-world social contacts (Kardefelt-Winther, 2014). That is, the limitless identity possibilities offered in games may distort players' perceptions of themselves and their true capabilities. If real-world engagement with peers and exploration of future alternatives is neglected, sound commitments will be difficult to establish.

Despite the aforementioned studies that have connected digital engagement with social and cognitive development and suggest its importance for different aspects of personal identity, there are few empirical studies specifically targeting the links between digital engagement and identity processes. In fact, only recently Bacchini, De Angelis, and Fanara (2017), using the three-dimensional identity measure by Crocetti et al. (2008), showed that excessive gaming is negatively associated with commitments and positively related to reconsideration of commitments, indicating a relationship between uncertainty in identity domains and gaming. However, the study focused only on excessive gaming and lacked a person-oriented approach to identity, that is, combinations of identity processes were not examined. To our knowledge, there are no studies to date exploring in detail if diverse measures of digital engagement are related to identity statuses.

\section{The Current Study}

The aim of this study was to investigate possible links between identity statuses and digital engagement, operationalized as digital skills, gaming seriousness, friendship- and interest-driven internet activities and excessive ICT use. Employing a person-oriented approach, we used the DIDS domain of general future plans to classify adolescents into identity statuses. 
Prior to examination of the main research question, we first created the identity profiles with LPA. In line with previous studies (e.g., Luyckx et al., 2008; Schwartz et al., 2011), we expected to find five or six of the following profiles: achievement, foreclosure, searching moratorium, ruminative moratorium, troubled diffusion, carefree diffusion and undifferentiated.

Our main research question was to determine if digital engagement is related to identity statuses, more specifically, latent profiles of commitment to and exploration of future plans. Based on previous studies and the assumed link between digital engagement and adolescent development (Bacchini et al., 2017; Ito et al., 2009; Manago, 2015), we hypothesized that individuals with high commitment profiles (foreclosure, searching moratorium, and achievement in particular), would show the highest friendship- and interest-driven internet activity, least preference for gaming, best digital skills and least excessive ICT use (H1). Achieved individuals already have future plans with which they are content. Because they have solved the task of direction, they feel no urge to escape confusion and social pressure by engaging in gaming or addictive digital activities. Instead, they display balanced digital engagement, that is, they network with others to share information and learn more about their commitments online while simultaneously building more advanced digital skills that further increase the possibility of them attaining future goals.

Based on existing research, we also hypothesized that subjects in the moratorium status would display intermediate levels of friendship- and interest-driven internet activity as well as digital skills, but also score highest on gaming and excessive ICT use ( $\mathrm{H} 2)$. These individuals have only weak or few commitments to discuss with others online and lack the motivation to develop better digital skills. Instead, high rumination provokes an escape into digital entertainment and addictive behaviours.

Finally, our last hypothesis was that diffused individuals would exhibit the least friendship- and interest-driven internet activities, the weakest digital skills and intermediate levels of gaming and ICT addiction (H3). The lack of future direction and relative disinterest in achieving one yield low motivation to engage in any socio-digital activities or development of related skills. Due to relatively low rumination, neither gaming nor general ICT addictive behaviours are present. We had no hypotheses for the other statuses, expecting them to fall somewhere in between the others. Finally, we controlled for gender, parental SES and life satisfaction in all the above analyses because previous studies have shown these to moderate digital engagement (Heinz, 2016; e.g., Przybylski, 2014; Robinson et al., 2015).

\section{Method}

\section{Participants and Context}

Finnish children have 9 years of comprehensive school, after which they, based on their academic achievement, can apply for either general upper secondary (high school; academic track) or vocational upper secondary education (vocational track). In 2012, every second student (50\%) entered high school, and a little less than that enrolled in vocational school (42\%: Official Statistics of Finland, 2016). Participants in this study were 932 secondyear high school students attending 16 different schools in the Helsinki metropolitan area in 2014 ( $M_{\text {age }}=17.1, S D$ $=0.29 ; 69 \%$ women). The majority (91\%) were native speakers of Finnish or Swedish. The students completed the self-report questionnaire during school hours, participation was voluntary and informed consent was obtained from their parents.

Our sample consisted of somewhat more privileged and academically successful adolescents. The grade point average of the sample was 9 (range 4-10; $S D=0.66)$, which was significantly above the academic mean $(M=8.15$, $S D=0.40)$ in the area. Further, parents' occupation displayed a bias towards higher SES among both mothers $(N=$ 508 ) and fathers ( $N=534$; blue-collar $=9 \% / 19 \%$, lower white-collar $=43 \% / 31 \%$ and upper white-collar $=48 \% / 50 \%$, respectively).

\section{Measures}

Identity. Identity formation and evaluation were measured using the short 11 -item version of the Dimensions of Identity Development Scale [DIDS] previously applied by Marttinen, Dietrich, and Salmela-Aro (2016; see Luyckx et 
al., 2008 for original full version). The DIDS comprises five subscales assessing commitment and exploration in the domain of general future plans: Commitment making ("I have decided on the direction I'm going to follow in my life"), identification with commitment ("My future plans give me self-confidence"), exploration in breadth ("I think actively about different directions I might take in my life"), exploration in depth ("I think about the future plans I already made") and ruminative exploration ("I worry about what I want to do with my future"). The short version of the DIDS contains two items per dimension, with the exception of three for ruminative exploration. The response scale ranges from 1 (strongly disagree) to 5 (strongly agree). Only for exploration in depth was the alpha score lower than .70 (i.e., .52), even if acceptable considering the number of items and moderate inter-item correlation (.35). Clark and Watson (1995) recommended that inter-item correlations fall within .15 and .50 for acceptable internal consistency. Means, standard deviations and reliability scores for all variables are found in Table 1.

Digital skills. Digital skills were measured with 9 items previously used by Hakkarainen et al. (2000) and Hietajärvi, Tuominen-Soini, Hakkarainen, Salmela-Aro, and Lonka (2015). Some items of the scale assess basic skills ("How competent do you see yourself in editing text documents") and others advanced skills ("How competent do you see yourself in programming"). The response scale ranges from 1 (not at all) to 5 (very fluent). A total score was computed for digital skills.

Internet participation. Students' internet activities were assessed with the 24-item Socio-Digital Participation Inventory (SDPi) employed by Hietajärvi, Seppä, and Hakkarainen (2017) and Moisala et al. (2017). We examined four subscales: social networking ("I update my "status" or share interesting things (pictures/links) with others in social media (Facebook, Whatsapp, Twitter), knowledge-oriented ("I search for new information about my hobbies or things I'm interested in"), media-oriented ("I share my own creations (text, videos, picture, music) with others") and technology-oriented ("I create websites for others"). Based on theory and interpretation, the subscales of knowledge, media and technology-oriented were further combined to represent a general interest-driven digital activities construct, whereas social networking represented friendship-driven activities. The SDPi uses a Likert scale for responses, ranging from 1 (never) to 7 (all the time).

Gaming seriousness. Seriousness of gaming was measured with six items, including "Gaming is a very important hobby for me". The response scales range from 1 (completely disagree) to 7 (completely agree).

Excessive ICT use. Compulsive and harmful digital technology use was assessed with a 5-item scale earlier employed by Salmela-Aro, Upadyaya, Hakkarainen, Lonka, and Alho (2017). A sample item reads, "Using ICT causes me to neglect my schoolwork". Responses range from 1 (completely disagree) to 5 (completely agree).

Life satisfaction. As a control variable, the 5-item Satisfaction with Life Scale (SWLS) was used to assess life satisfaction (Diener, Emmons, Larsen, \& Griffin, 1985). One such item is, "I am satisfied with my life," and the response scale ranges from 1 (completely disagree) to 7 (completely agree).

\section{Results}

\section{Preliminary Results}

Examining the means in Table 1, the results suggest that friendship-driven activity was more popular than interestdriven activity, as previously found (e.g., Ito et al., 2009). However, serious gaming was not common among the participants. Moving on to correlations, gaming displayed no associations with the identity processes, whereas digital skills were negatively associated with ruminative exploration and positively with the other identity processes. Further, friendship-driven internet activity showed modest positive correlations with commitment processes and in-depth exploration. In contrast, interest-driven activity was positively associated with all three exploration processes. This distinction in internet activity was supported by the finding that friendship-driven activity was positively related to life satisfaction, whereas interest-driven activity was negatively related. 
Table 1. Descriptives, Internal Consistencies and Bivariate Correlations ( $N=932)$.

\begin{tabular}{|c|c|c|c|c|c|c|c|c|c|c|c|}
\hline & 1 & 2 & 3 & 4 & 5 & 6 & 7 & 8 & 9 & 10 & 11 \\
\hline $\begin{array}{l}\text { 1. Commitment } \\
\text { making }\end{array}$ & - & & & & & & & & & & \\
\hline $\begin{array}{l}\text { 2. Identification with } \\
\text { commitment }\end{array}$ & $.67 * \star \star$ & - & & & & & & & & & \\
\hline $\begin{array}{l}\text { 3. Exploration in } \\
\text { breadth }\end{array}$ & $.21 * \star \star$ & $.25^{\star \star \star}$ & - & & & & & & & & \\
\hline $\begin{array}{l}\text { 4. Exploration in } \\
\text { depth }\end{array}$ & $.20 * \star \star$ & $.20 * \star \star$ & $.38 * \star \star$ & - & & & & & & & \\
\hline $\begin{array}{l}\text { 5. Ruminative } \\
\text { exploration }\end{array}$ & 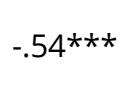 & $-.42 * \star \star$ & $.07 *$ & $.30 * \star \star$ & - & & & & & & \\
\hline 6. Life satisfaction & $.29 * * *$ & $.28 * \star *$ & $.07 *$ & $-.12 * \star$ & $-.35 * * *$ & - & & & & & \\
\hline 7. Digital skills & $.14 * \star \star$ & $.13 * * *$ & $.15 * \star \star$ & $.12 * \star \star$ & $-.08 *$ & .04 & - & & & & \\
\hline 8. Gaming & -.04 & -.04 & .01 & -.03 & -.04 & -.05 & $.18 * * *$ & - & & & \\
\hline 9. Friendship-driven & $.07 *$ & $.07 *$ & .05 & $.10 * *$ & .03 & $.09 * *$ & $.22 * \star *$ & $-.17 * \star *$ & - & & \\
\hline 10. Interest-driven & -.01 & .01 & $.11 * \star \star$ & $.15^{* \star *}$ & $.10 * *$ & $-.15^{\star \star \star}$ & $.43 * \star \star$ & $.08 *$ & $.33 * \star \star$ & - & \\
\hline 11. Excessive ICT use & $-.14 * \star \star$ & $-.09 * *$ & .01 & $.18 * \star \star$ & $.24 * * \star$ & $-.20 * \star \star$ & $.10 * *$ & $.24 * * *$ & $.12 * \star \star$ & $.20 * \star \star$ & - \\
\hline$M$ & 3.13 & 3.14 & 3.80 & 3.46 & 3.06 & 4.78 & 3.54 & 1.83 & 4.14 & 1.70 & 2.94 \\
\hline$S D$ & 1.18 & 1.11 & .81 & .93 & 1.10 & 1.32 & .59 & 1.29 & .93 & .52 & 1.22 \\
\hline Cronbach's alpha & .93 & .90 & .72 & .52 & .84 & .89 & .79 & .86 & .71 & .71 & .82 \\
\hline
\end{tabular}

Note: Pearson correlations used. ${ }^{* *}=p \leq .001 ;{ }^{* *}=p \leq .01 ;{ }^{*}=p \leq .05$.

Identity profiles. A confirmatory factor analysis indicated sufficient fit of the five-dimensional model $\left(\chi^{2}(34, N=\right.$ $922)=313.743, p<.000$, RMSEA $=.09(90 \% \mathrm{Cl}=.085-.104), \mathrm{CFI}=.94, \mathrm{SRMR}=.09)$. Next, groups of individuals with similar response combinations on the identity dimensions were identified through LPA (Mplus 7.31: see Bergman, Magnusson, \& El-Khouri, 2003). The fit indices (sample-size adjusted Bayesian information criterion [SA-BIC], lower scores indicating better fit; Vuong-Lo-Mendell-Rubin [VLMR] nested model comparison, $p$ value below .05, suggesting that the estimated model should be favoured over a model with one less profile), theoretical meaningfulness, parsimony and resemblance of profiles with previous results supported a five-profile solution. The LPA results are located in Table 2.

Table 2. Information Criteria Values for the Different Profile Solutions.

\begin{tabular}{ccccr}
\hline $\begin{array}{c}\text { Number of } \\
\text { profiles }\end{array}$ & SA-BIC & pVLMR & Entropy & $\begin{array}{c}\text { Size of the latent profile } \\
\text { group }\end{array}$ \\
\hline 1 & 12993.181 & & & 911 \\
2 & 12279.562 & .00 & .75 & 433478 \\
3 & 12062.464 & .00 & .78 & 406246262 \\
4 & 11924.617 & .08 & .74 & 240122253296 \\
5 & 11783.891 & .00 & .75 & 186144322138121 \\
6 & 11723.482 & .11 & .75 & 159287104118100143 \\
7 & 11706.848 & .18 & .76 & 2414413113828091103 \\
8 & 11686.587 & .76 & .75 & 81114132171208619351 \\
\hline
\end{tabular}

Note: $\mathrm{SA}-\mathrm{BIC}=$ Sample-size adjusted Bayesian information criterion; VLMR = Vuong-Lo-Medell-Rubin likelihood ratio test. Selected solution is in italics.

The identified profiles were Achievement ( $N=186,20.4 \%$, high on both commitment dimensions and intermediate to low on all the exploration dimensions), Searching Moratorium ( $N=121,13.3 \%$, high on all dimensions), Early Closure ( $N=322,35.4 \%$, heightened commitment, intermediate scores on the other dimensions), Ruminative Moratorium ( $N=138,15.2 \%$, low scores on both commitment dimensions and intermediate to high scores on all the exploration dimensions) and Diffusion ( $N=143,15.7 \%$, low scores on all dimensions except a moderately high score on ruminative exploration). Figure 1 illustrates the profiles, with the $y$-axis representing $z$ scores (i.e., standard deviations). In line with Cohen's $d$ (1988), the $z$ scores were interpreted as effect sizes, where a SD of 0.2 is considered a small effect, a $S D$ of 0.5 a moderate effect and a $S D$ of 0.8 as a large effect. 
1,50000

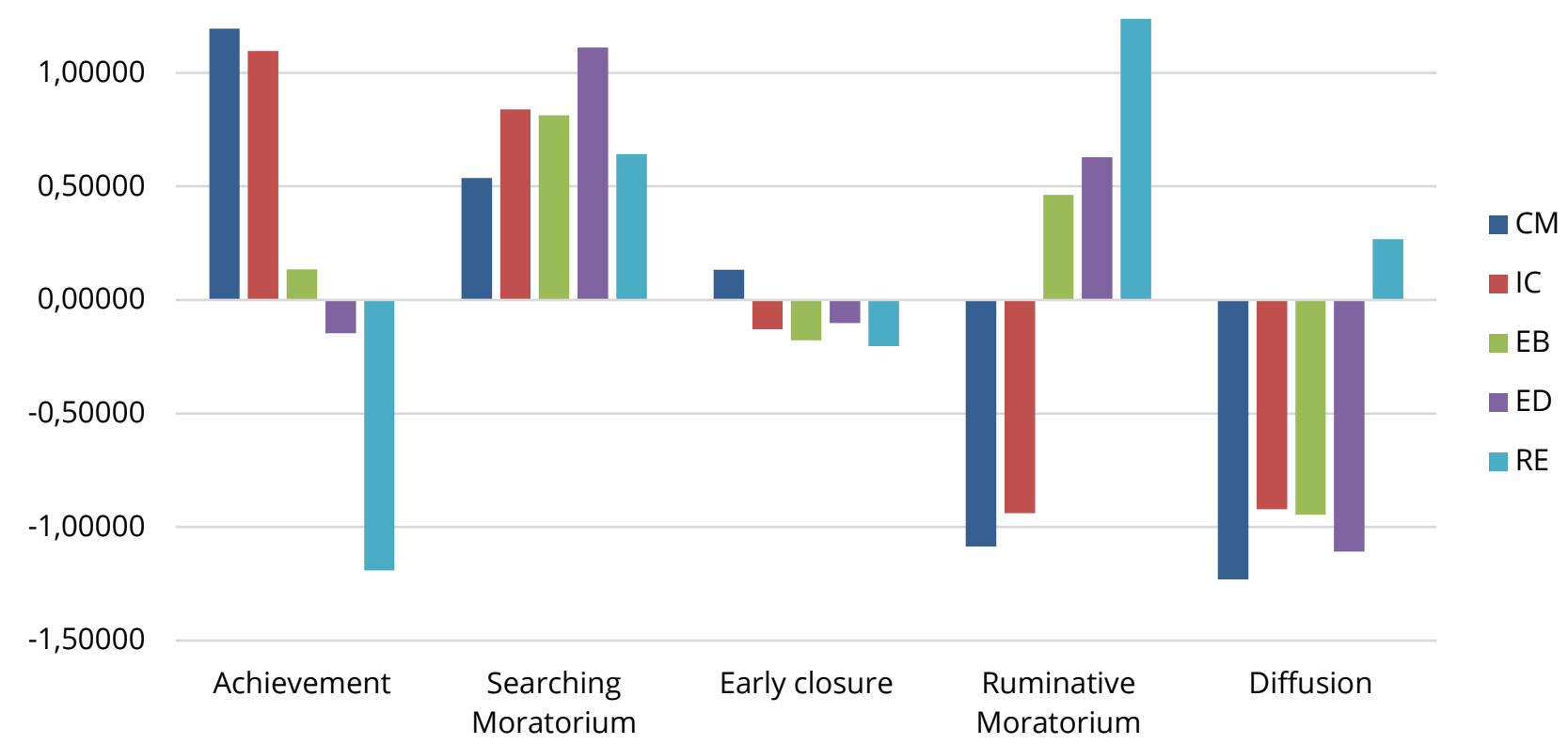

Figure 1. The final latent profile solution $(N=910)$. $Z$ scores for commitment making $(C M)$, identification with commitment (IC), exploration in breadth (EB), exploration in depth (ED) and ruminative exploration (RE).

\section{Identity Profiles and Digital Engagement}

A multivariate ANCOVA was conducted to analyse the main effect of identity profile on digital engagement while controlling for gender, SES and life satisfaction. Prior to the analyses, 12 univariate outliers with +-3 SDs were deleted from the variables assessing digital engagement. Moreover, because only half of our sample $(N=502)$ reported a parental SES value, we were not able to use SES as a covariate in the analyses of the entire sample. Instead we first performed a check in the SES-subsample to determine whether the results held with and without SES. Controlling for SES, gender and life satisfaction in the subsample, we found a main effect of identity profile $($ Wilks' $\lambda=.90, F(20,1612.830)=2.604, p<.001 ; \eta p 2=.03)$. However, no interaction effect between identity and gender existed (Wilks' $\left.\lambda=.95, F(20,1612.830)=1.281, p>.05 ; \eta_{p}^{2}=.01\right)$. The results held even with SES excluded. Thus, because SES had no effect on the analyses carried out on this sub-sample, we moved on to examine the whole sample with SES excluded from the analyses.

As we expected, we found a significant main effect of identity profile on digital engagement while controlling for gender and life satisfaction (Wilks' $\lambda=.93, F(20,2461.885)=2.735, p<.000 ; \eta_{p}{ }^{2}=.02$ ). More specifically, the main effects were very modest and only existed for digital skills, friendship-driven internet activity and excessive ICT use (see Table 3 for results). Regarding digital skills, the results supported all our hypotheses: adolescents in the achievement and searching moratorium statuses scored highest, diffused adolescents the lowest and those in ruminative moratorium had intermediate scores. In contrast, for friendship-driven activity, only our third hypothesis gained support, that is, diffused adolescents scored lowest. Unexpectedly, respondents in the ruminative moratorium scored highest, not the individuals in achievement. Furthermore, all our hypotheses gained support concerning excessive ICT use, as adolescents in achievement scored lowest, adolescents in ruminative moratorium highest and diffused ones intermediate. No interaction effect occurred with gender (Wilks' $\left.\lambda=.96, F(20,2461.885)=1.422, p>.05 ; W_{i l k s}^{\prime} \lambda=.96 ; \eta_{p}^{2}=.01\right)$.

Finally, but unrelated to our hypotheses, differences in interest-driven internet activity between the profiles became significant if gender was left out, with searching moratorium scoring significantly higher than achievement and diffusion $\left(F=2.965, p>.05 ; \eta_{p}^{2}=.015\right)$. Similarly, gaming seriousness became significant if life satisfaction was omitted, with ruminative moratorium scoring significantly higher than achievement $\left(F=4.004, p>.01 ; \eta_{p}^{2}=.021\right)$. 
Table 3. MANCOVA with Pairwise Comparisons for the Five Profiles and Digital Engagement $(N=757)$.

\begin{tabular}{lccccccc}
\hline Variables & Profiles & & & & F-value & $\boldsymbol{\eta}^{2}$ \\
\cline { 2 - 6 } & Achievement & $\begin{array}{c}\text { Searching } \\
\text { Moratorium }\end{array}$ & $\begin{array}{c}\text { Early } \\
\text { closure }\end{array}$ & $\begin{array}{c}\text { Ruminative } \\
\text { Moratorium }\end{array}$ & Diffusion & & \\
\hline Digital skills & $3.67^{\mathrm{b}}(.67)$ & $3.67^{\mathrm{b}}(.61)$ & $3.56(.55)$ & $3.47(.54)$ & $3.36^{\mathrm{a}}(.52)$ & $4.197^{\star \star \star *}$ & .026 \\
Gaming seriousness & $1.76(1.23)$ & $1.68(1.00)$ & $1.87(1.19)$ & $1.91(1.26)$ & $1.88(1.21)$ & 2.147 & .011 \\
Friendship-driven activity & $4.22(.82)$ & $4.16(.96)$ & $4.11(.92)$ & $4.24^{\mathrm{b}}(.88)$ & $3.95^{\mathrm{a}}(1.00)$ & $2.670^{*}$ & .014 \\
Interest-driven activity & $1.63(.45)$ & $1.82(.56)$ & $1.71(.49)$ & $1.78(.47)$ & $1.63(.40)$ & 1.349 & .007 \\
Excessive ICT use & $2.65^{\mathrm{a}}(.11)$ & $2.98(1.02)$ & $2.97(1.28)$ & $3.41^{\mathrm{b}}(1.17)$ & $2.93(1.23)$ & $3.046^{*}$ & .016 \\
\hline
\end{tabular}

Note: A profile mean is significantly different from another mean within the same row if they have different superscripts. A mean without a superscript is not significantly different from any other mean. Standard deviations are in parentheses. $* * *=p \leq .001 ; * \star=p \leq .01$; $*=p \leq .05$.

\section{Discussion}

Today, western adolescents face new social and economic uncertainties that make identity consolidation a prolonged and precarious task. In these circumstances, digital engagement may both advance and impede exploration of and commitment to future plans. Employing a person-oriented approach in this study, we set out to test whether adolescents' identity profiles are linked with their digital technology and media use.

First, latent profile analyses yielded five identity profiles identified also in previous studies (e.g., Schwartz et al., 2011). It is worthy of note that in this study the achievement profile showed relatively weak exploration of alternatives, as has been observed in other studies (Skhirtladze, Javakhishvili, Schwartz, Beyers, \& Luyckx, 2016). In some contexts, if future plans are present, it might be more adaptive for individuals to remain completely focused on those plans rather than be open to alternatives. As with individuals in the searching moratorium, the risk of uncertainty is heightened rumination. Further, in this study, the exploration in depth dimension acted in a similar manner to ruminative exploration, which might explain the relatively low levels displayed by identityachieved adolescents.

Second, but more importantly, our main hypotheses were only partially supported. Regardless of gender, life satisfaction and parental SES, identity profile had a significant effect on three out of five digital engagement indicators. As we expected, adolescents actively searching for and maintaining commitments (even with some rumination as in the case of searching moratorium) had the most advanced digital skills, whereas diffused individuals had the worst (i.e., communication, graphic design, video editing, programming). In line with Manago (2015), this suggests that for adolescents targeting specific goals, digital technology constitutes a purposeful tool for developing new necessary skills as well as practice for shaping future opportunities and eventually achieving those goals.

Furthermore, as we hypothesized, adolescents lacking commitments and desperately looking for a direction in life (ruminative moratorium) showed the greatest excessive ICT use, and achieved individuals showed the least. That is, when facing future uncertainty and experiencing rumination, adolescents also display distressed and compulsive digital technology behaviour that interferes with areas such as schoolwork and sleep rhythm. Although our measure did not discriminate between different forms of digital engagement (e.g., social networking, gaming), this finding is congruent with previous studies on how identity uncertainty and psychosocial problems are linked with addictive digital technology use (Bacchini et al., 2017; Kardefelt-Winther, 2014). Excessive ICT use was also negatively correlated with life satisfaction.

Interestingly, in this study, the finding that digital engagement was compulsive and anxious when more broad and ruminative identity exploration was present, implies that digital engagement was not pure escapism but instead an emotionally invested coping strategy for exploring and establishing commitments. This interpretation is supported by our other findings, namely, that identity profiles displayed no differences in gaming and that adolescents in ruminative moratorium, contrary to our hypotheses, scored highest on friendship-driven internet activity. Namely, friendship-driven activity was positively correlated with exploration in depth, that is, reflecting on chosen commitments. Accordingly, the results suggest that these adolescents use peer support in digital social networks to explore and reflect on possible future paths. Identity-diffused adolescents, on the other hand, are 
disinterested in developing future plans and also lack interest in any forms of digital engagement. In other words, excessive digital engagement is not necessarily detrimental if the goal is or will be solving a task. Relatedly, and somewhat contrary to previous studies (e.g., Gentile et al., 2012; Haferkamp \& Krämer, 2011; Misra \& Stokols, 2012), in this study friendship-driven internet activity was positively associated with life satisfaction, indicating that social networking was not harmful but instead supportive of well-being.

Finally, unless covariates were excluded, no differences were found between the profiles regarding interest-driven internet activity and gaming. This was somewhat surprising in the former case because adolescents in achievement were expected to actively develop and maintain their future plans using the internet. This outcome was, however, most likely due to the relatively low level of exploration among adolescents in achievement. Overall, taking correlation patterns and profile differences into account, interest-driven activity was linked with exploration of future plans, as we originally theorized. In the case of gaming seriousness, although gaming was positively correlated with ruminative exploration and thus reflective of previous findings (Bacchini et al., 2017), our results suggested that well-being was a slightly stronger predictor of gaming than status. When controlling for life satisfaction, gaming emerged as a rather neutral activity with similar levels across statuses.

Other possible explanations for the non-existent and modest effect sizes include sample characteristics. As mentioned, for some time the Finnish government has already invested heavily into improving adolescents' digital skills. Consequently, Finnish adolescents are very similar in their digital skills and use. Further, the sample was rather biased in terms of parental SES and previous school success. In other words, large differences in digital engagement or exploration and commitment levels might not emerge in such a uniform sample (OECD, 2016). Unfortunately, we did not have access to results including adolescents on a vocational track or from more diverse backgrounds.

Overall, our results support previous theory and empirical findings on how digital practices inextricably reflect and shape social behaviour and development (Ito et al., 2009; Manago, 2015). In the present study, digital engagement was meaningfully linked with identity status. In contrast to a variable-approach (Bacchini et al., 2017), the personoriented approach indicated that good digital skills, internet activity or excessive ICT use are not solely dependent on anxious exploration, but also on the levels of existing commitment (searching moratorium). Provided that identity is dynamic and multidirectional, our results suggest that digital engagement may add to positive identity development as much as firm future commitments may launch interest in connecting digitally with others and with information. Adolescents anxiously searching for a direction in life and trying to stabilize an identity use digital technology to a greater extent (also excessively) than before commencing this task or after completing it.

The present results have their limitations. First, our cross-sectional sample did not address causality or identity development but simply gave a snapshot of current identity status and related correlates. Second, and as discussed above, our sample contained only high school students from the Helsinki metropolitan region who had relatively high GPAs and higher SES background and voluntarily took part in the self-report study. In other words, differences that did or did not emerge between the profiles may, therefore, be an outcome of demographic or individual bias, ungeneralizable to other adolescents. Thus, we recommend that future research employ longitudinal data for causality evaluation, recruit a more diverse sample and, in addition, develop a multidimensional measure for excessive ICT use that better indicates which types or patterns of excessive behaviours (e.g., gaming, social networking) are detrimental and which are not.

Nonetheless, the present findings have policy implications. If digital practices can support positive identity formation, as our results indicate, then an important societal investment would be proper ICT education in schools. Schools should ensure that students are equally skilled in the use of digital technology and encourage identity exploration using digital devices. This would insure more equal life path opportunities, benefit adolescents' identity development and combat marginalization on a national level.

\section{Conclusion}

Our study is the first to demonstrate that identity statuses, that is, specific configurations of identity exploration and commitments, are related to digital engagement. In other words, how adolescents cope with identity issues is also reflected in their digital practices. More specifically, our results suggest that adolescents interested in 
developing and maintaining future commitments are more engaged in digital technology than adolescents lacking exploration or commitments (i.e., diffusion). Commitments in combination with moderate exploration (i.e., achievement, searching moratorium) had the best digital skills, whereas those lacking commitments but high in exploration (i.e., ruminative moratorium) were most strongly into social networking but also showed excessive ICT use. In conclusion, the associations between identity profiles and digital engagement suggest that positive identity development can be supported by digital engagement and competence.

\section{Acknowledgements}

This research was supported by the Academy of Finland research grants 298323, 308351 and 273872 to Katariina Salmela-Aro.

\section{References}

Anderson, C. A. (2014). Violent, nonviolent, and prosocial gaming effects on teens' civic engagement. In Oxford handbooks online. New York: Oxford University Press.

Arnett, J. J. (2004). Emerging adulthood: The winding road from the late teens through the twenties. New York, NY: Oxford University Press.

Bacchini, D., De Angelis, G., \& Fanara, A. (2017). Identity formation in adolescent and emerging adult regular players of massively multiplayer online role-playing games (MMORPG). Computers in Human Behavior, 73, 191199. https://doi.org/10.1016/j.chb.2017.03.045

Bergman, L. R., Magnusson, D., \& El-Khouri, B. (2003). Studying individual development in an interindividual context: A person-oriented approach. Mahwah, NJ: Erlbaum.

City of Helsinki. (2016). Helsingin kaupungin opetuksen digitalisaatio-ohjelma vuosille 2016-2019 [The Helsinki city digitalisation program of education for years 2016-2019]. Retrieved from

https://www.hel.fi/static/liitteet/opev/Opetusvirasto_Digitalisaatiohanke_Webjulkaisu_FINAL.pdf

Clark, L. A., \& Watson, D. (1995). Constructing validity. Psychological Assessment, 7, 309-319.

https://doi.org/10.1037/1040-3590.7.3.309

Cohen, J. (1988). Statistical power analysis for the behavioral sciences. Hillsdale, NJ: Erlbaum.

Côté, J. E. (2006). Emerging adulthood as an institutionalized moratorium: Risks and benefits to identity formation. In J. J. Arnett \& J. L. Tanner (Eds.), Emerging adults in America: Coming of age in the 21st century (pp. 85116). Washington, DC: American Psychological Association.

Crocetti, E., \& Meeus, W. (2015). The identity statuses: Strengths of a person-centered approach. In K. McLean, \& M. Syed (Eds.), The Oxford handbook of identity development (pp. 97-114). New York, NY: Oxford University Press.

Crocetti, E., Rubini, M., \& Meeus, W. (2008). Capturing the dynamics of identity formation in various ethnic groups: Development and validation of a three-dimensional model. Journal of Adolescence, 31, 207-222. https://doi.org/10.1016/j.adolescence.2007.09.002

Curran, J., Fenton, N., \& Freedman, D. (2016). Misunderstanding the internet. New York: Routledge.

Diener, E. D., Emmons, R. A., Larsen, R. J., \& Griffin, S. (1985). The satisfaction with life scale. Journal of Personality Assessment, 49, 71-75. https://doi.org/10.1207/s15327752jpa4901_13

Elliott, A. (2015). Identity troubles: An introduction. London: Routledge.

Erikson, E. (1950). Childhood and society. New York, NY: Norton.

Erikson, E. (1968). Identity: Youth and crisis (2. print. ed.). New York, NY: Norton.

Eynon, R., \& Malmberg, L. (2011). A typology of young people's Internet use: Implications for education.

Computers \& Education, 56, 585-595. https://doi.org/10.1016/j.compedu.2010.09.020

Fadjukoff, P. (2007). Identity formation in adulthood. Jyväskylä: University of Jyväskylä. 
Fadjukoff, P., Kokko, K., \& Pulkkinen, L. (2010). Changing economic conditions and identity formation in adulthood. European Psychologist, 15, 293-303. https://doi.org/10.1027/1016-9040/a000061

Gabbiadini, A., \& Greitemeyer, T. (2017). Uncovering the association between strategy video games and selfregulation: A correlational study. Personality and Individual Differences, 104, 129-136.

https://doi.org/10.1016/j.paid.2016.07.041

Gallardo-Echenique, E. E., de Oliveira, J. M., Marqués-Molias, L., \& Esteve-Mon, F. (2015). Digital competence in the knowledge society. Journal of Online Learning and Teaching, 11, 1-16.

Gentile, B., Twenge, J. M., Freeman, E. C., \& Campbell, W. K. (2012). The effect of social networking websites on positive self-views: An experimental investigation. Computers in Human Behavior, 28, 1929-1933.

https://doi.org/10.1016/j.chb.2012.05.012

Gentile, D. A., Coyne, S. M., \& Bricolo, F. (2013). Pathological technology addictions: What is scientifically known and what remains to be learned. In E. Dill (Ed.), The Oxford handbook of media psychology (pp. 382-402).

Gonzales, A. L., \& Hancock, J. T. (2008). Identity shift in computer-mediated environments. Media Psychology, 11, 167-185. https://doi.org/10.1080/15213260802023433

Green, C. S., Gorman, T., \& Bavelier, D. (2016). Action video-game training and its effects on perception and attentional control. In T. Strobach \& J. Karbach (Eds.), Cognitive training (pp. 107-116). Heidelberg: Springer.

Greitemeyer, T., \& Mügge, D. O. (2014). Video games do affect social outcomes a meta-analytic review of the effects of violent and prosocial video game play. Personality and Social Psychology Bulletin, 40, 578-589. https://doi.org/10.1177/0146167213520459

Haferkamp, N., \& Krämer, N. C. (2011). Social comparison 2.0: Examining the effects of online profiles on socialnetworking sites. Cyberpsychology, Behavior, and Social Networking, 14, 309-314.

https://doi.org/10.1089/cyber.2010.0120

Hakkarainen, K. (2009). A knowledge-practice perspective on technology-mediated learning. International Journal of Computer-Supported Collaborative Learning, 4, 213-231. https://doi.org/10.1007/s11412-009-9064-x

Hakkarainen, K., Ilomäki, L., Lipponen, L., Muukkonen, H., Rahikainen, M., Tuominen, T., ... Lehtinen, E. (2000). Students' skills and practices of using ICT: Results of a national assessment in Finland. Computers \& Education, 34, 103-117. https://doi.org/10.1016/S0360-1315(00)00007-5

Heinz, J. (2016). Digital skills and the influence of students' socio-economic background. An exploratory study in German elementary schools. Italian Journal of Sociology of Education, 8(2), 186-212. https://doi.org/10.14658/pupjijse-2016-2-9

Hietajärvi, L., Seppä, J., \& Hakkarainen, K. (2017). Dimensions of adolescents' socio-digital participation. QwertyOpen and Interdisciplinary Journal of Technology, Culture and Education, 11(2), 79-98.

Hietajärvi, L., Tuominen-Soini, H., Hakkarainen, K., Salmela-Aro, K., \& Lonka, K. (2015). Is student motivation related to socio-digital participation? A person-oriented approach. Procedia-Social and Behavioral Sciences, 171, 1156-1167. https://doi.org/10.1016/j.sbspro.2015.01.226

Ito, M., Baumer, S., Bittanti, M., Cody, R., Stephenson, B. H., Horst, H. A., .. Pascoe, C. J. (2009). Hanging out, messing around, and geeking out: Kids living and learning with new media. Cambridge, MA: MIT Press.

Kardefelt-Winther, D. (2014). The moderating role of psychosocial well-being on the relationship between escapism and excessive online gaming. Computers in Human Behavior, 38, 68-74.

https://doi.org/10.1016/j.chb.2014.05.020

Kennedy, G., Judd, T., Dalgarno, B., \& Waycott, J. (2010). Beyond natives and immigrants: Exploring types of net generation students. Journal of Computer Assisted Learning, 26, 332-343. https://doi.org/10.1111/j.1365-

2729.2010.00371.x

Kroger, J. (1997). Gender and identity: The intersection of structure, content, and context. Sex Roles, 36, 747-770. 
Kroger, J., \& Marcia, J. E. (2011). The identity statuses: Origins, meanings, and interpretations. In S. J. Schwartz, K. Luyckx, \& V. L. Vignoles (Eds.), Handbook of identity theory and research (pp. 31-53). New York, NY: Springer New York. https://doi.org/10.1007/978-1-4419-7988-9_2

Kroger, J., Martinussen, M., \& Marcia, J. E. (2010). Identity status change during adolescence and young adulthood: A meta-analysis. Journal of Adolescence, 33, 683-698.

https://doi.org/10.1016/j.adolescence.2009.11.002

Luyckx, K., Duriez, B., Klimstra, T. A., \& De Witte, H. (2010). Identity statuses in young adult employees: Prospective relations with work engagement and burnout. Journal of Vocational Behavior, 77, 339-349. https://doi.org/10.1016/j.jvb.2010.06.002

Luyckx, K., Goossens, L., \& Soenens, B. (2006). A developmental contextual perspective on identity construction in emerging adulthood. Developmental Psychology, 42, 366-380. https://doi.org/10.1037/0012-1649.42.2.366

Luyckx, K., Goossens, L., Soenens, B., \& Beyers, W. (2006). Unpacking commitment and exploration: Preliminary validation of an integrative model of late adolescent identity formation. Journal of Adolescence, 29, 361-378. https://doi.org/10.1016/j.adolescence.2005.03.008

Luyckx, K., Schwartz, S. J., Berzonsky, M. D., Soenens, B., Vansteenkiste, M., Smits, I., \& Goossens, L. (2008). Capturing ruminative exploration: Extending the four-dimensional model of identity formation in late adolescence. Journal of Research in Personality, 42, 58-82. https://doi.org/10.1016/j.jrp.2007.04.004

Luyckx, K., Seiffge-Krenke, I., Schwartz, S. J., Crocetti, E., \& Klimstra, T. A. (2014). Identity configurations across love and work in emerging adults in romantic relationships. Journal of Applied Developmental Psychology, 35, 192203. https://doi.org/10.1016/j.appdev.2014.03.007

Manago, A. M. (2015). Identity development in the digital age: The case of social networking sites. In K. C. McLean, \& M. Syed (Eds.), The Oxford handbook of identity development (pp. 508-526). Oxford: Oxford University Press. https://doi.org/10.1093/oxfordhb/9780199936564.013.031

Mannerström, R., Hautamäki, A., \& Leikas, S. (2016). Identity status among young adults: Validation of the dimensions of identity development scale (DIDS) in a Finnish sample. Nordic Psychology, 69, 195-213.

https://doi.org/10.1080/19012276.2016.1245156

Marcia, J. E. (1966). Development and validation of ego-identity status. Journal of Personality and Social Psychology, 3, 551-558. https://doi.org/10.1037/h0023281

Marcia, J. E. (1993). The ego identity status approach to ego identity. In J. E. Marcia, A. S. Waterman, D. R. Matteson, S. L. Archer, \& J. L. Orlofsky (Eds.), Ego identity: A handbook for psychosocial research (pp. 1-21). New York, NY: Springer-Verlag.

Marttinen, E., Dietrich, J., \& Salmela-Aro, K. (2016). Dark shadows of rumination: Finnish young adults' identity profiles, personal goals and concerns. Journal of Adolescence, 47, 185-196.

https://doi.org/10.1016/j.adolescence.2015.10.024

Mastrotheodoros, S., \& Motti-Stefanidi, F. (2017). Dimensions of identity development scale (DIDS): A test of longitudinal measurement invariance in Greek adolescents. European Journal of Developmental Psychology, 14, 605-617. https://doi.org/10.1080/17405629.2016.1241175

Meeus, W., van de Schoot, R., Keijsers, L., Schwartz, S., \& Branje, S. J. T. (2010). On the progression and stability of adolescent identity formation. A five-wave longitudinal study in early-to-middle and middle-to-late adolescence. Child Development, 81, 1565-1581. https://doi.org/10.1111/j.1467-8624.2010.01492.x

Meeus, W., van de Schoot, R., Keijsers, L., \& Branje, S. (2012). Identity statuses as developmental trajectories: A five-wave longitudinal study in early-to-middle and middle-to-late adolescents. Journal of Youth and Adolescence, 41, 1008-1021. https://doi.org/10.1007/s10964-011-9730-y

Ministry of Education and Culture. (2016). New comprehensive education. Retrieved from https://minedu.fi/en/new-comprehensive-education

Misra, S., \& Stokols, D. (2012). Psychological and health outcomes of perceived information overload. Environment and Behavior, 44, 737-759. https://doi.org/10.1177/0013916511404408 
Moisala, M., Salmela, V., Hietajärvi, L., Carlson, S., Vuontela, V., Lonka, K., .. Alho, K. (2017). Gaming is related to enhanced working memory performance and task-related cortical activity. Brain Research, 1655, $204-215$. https://doi.org/10.1016/j.brainres.2016.10.027

Niemi, H. (2014). The Finnish educational ecosystem. In H. Niemi, J. Multisilta, L. Lipponen, \& M. Vivitsou (Eds.), Finnish innovations and technologies in schools (pp. 3-19). Rotterdam: SensePublishers.

Niemi, H., Kynäslahti, H., \& Vahtivuori-Hänninen, S. (2013). Towards ICT in everyday life in Finnish schools: Seeking conditions for good practices. Learning, Media and Technology, 38, 57-71.

https://doi.org/10.1080/17439884.2011.651473

Organisation for Economic Co-operation and Development. (2015). Education policy outlook. Retrieved from http://www.oecd.org/statistics/compare-your-country.htm

Organisation for Economic Co-operation and Development. (2016). Are there differences in how advantaged and disadvantaged students use internet? Retrieved from https://doi.org/10.1787/22260919

Official Statistics of Finland. (2016). Entrance to education. Retrieved from http://www.stat.fi/til/khak/2016/khak_2016_2017-12-13_tau_001_en.html

Prot, S., Anderson, C., Gentile, D. A., Brown, S. C., \& Swing, E. L. (2014). The positive and negative effects of video game play. In A. B. Jordan \& D. Romer (Eds.), Media and the well-being of children and adolescents (pp. 109-128). New York, NY: Oxford University Press.

Przybylski, A. K. (2014). Electronic gaming and psychosocial adjustment. Pediatrics, 134, 716-722. https://doi.org/10.1542/peds.2013-4021

Przybylski, A. K., \& Weinstein, N. (2017). A large-scale test of the Goldilocks Hypothesis: Quantifying the relations between digital-screen use and the mental well-being of adolescents. Psychological Science, 28, 204-215.

https://doi.org/10.1177/0956797616678438

Robinson, L., Cotten, S. R., Ono, H., Quan-Haase, A., Mesch, G., Chen, W., . . Stern, M. J. (2015). Digital inequalities and why they matter. Information, Communication \& Society, 18, 569-582.

https://doi.org/10.1080/1369118X.2015.1012532

Salmela-Aro, K., Upadyaya, K., Hakkarainen, K., Lonka, K., \& Alho, K. (2017). The dark side of internet use: Two longitudinal studies of excessive internet use, depressive symptoms, school burnout and engagement among Finnish early and late adolescents. Journal of Youth and Adolescence, 46, 343-357. https://doi.org/10.1007/s10964016-0494-2

Schwab, K. (2017). The fourth industrial revolution. Geneva: World Economic Forum.

Schwartz, S. J., Beyers, W., Luyckx, K., Soenens, B., Zamboanga, B. L., Forthun, L. F., . . Waterman, A. S. (2011). Examining the light and dark sides of emergent adult's identity: A study of identity status differences in positive and negative psychosocial functioning. Journal of Youth and Adolescence, 40, 839-859.

https://doi.org/10.1007/s10964-010-9606-6

Schwartz, S. J., Côté, J. E., \& Arnett, J. J. (2005). Identity and agency in emerging adulthood. Youth \& Society, 37, $201-$ 229. https://doi.org/10.1177/0044118X05275965

Skhirtladze, N., Javakhishvili, N., Schwartz, S. J., Beyers, W., \& Luyckx, K. (2016). Identity processes and statuses in post-Soviet Georgia: Exploration processes operate differently. Journal of Adolescence, 47, 197-209.

https://doi.org/10.1016/j.adolescence.2015.08.006

Trilling, B., \& Fadel, C. (2009). 21st century skills: Learning for life in our times. San Francisco, CA: Jossey-Bass cop.

van den Beemt, A., Akkerman, S., \& Simons, P. R. J. (2011). Patterns of interactive media use among contemporary youth. Journal of Computer Assisted Learning, 27, 103-118. https://doi.org/10.1111/j.1365-

2729.2010.00384.x

Waterman, A. S. (1982). Identity development from adolescence to adulthood: An extension of theory and a review of research. Developmental Psychology, 18, 341. https://doi.org/10.1037/0012-1649.18.3.341 
Zimmerman, G., Lannegrand-Willems, L., Safont-Mottay, C., \& Cannard, C. (2013). Testing new identity models and processes in French-speaking adolescents and emerging adult students. Journal of Youth and Adolescence, 44, 127-141. https://doi.org/10.1007/s10964-013-0005-7

\section{Correspondence to:}

Rasmus Mannerström

Department of Psychology, University of Jyväskylä

P.O.B. 35

FIN-40014

Finland

E-mail: rasmus.mannerstrom(at)helsinki.fi

Editorial record: First submission received on October 26, 2017. Revisions received on February 22, 2018, May 24, 2018, and July 2, 2018. Accepted for publication on July 3, 2018.

\section{About Authors}

Rasmus Mannerström, MSSc, is a doctoral candidate in psychology at the University of Jyväskylä, Finland. He is currently finishing his dissertation on personal identity and psychosocial correlates. His research interests include identity troubles, changes in masculinity, values and political engagement in late modern society.

Lauri Hietajärvi, M.Ed. is a doctoral researcher at the University of Helsinki, where he works at the Faculty of Educational Sciences. He is a member of the research group on Educational Psychology. His research interests include examining digital participation, connected learning, student motivation, and well-being as well as the psychological dynamics overlapping adolescents' life in and out of school.

Joona Muotka, M.A., is a university teacher and statistician at the Department of Psychology at the University of Jyväskylä, Finland. His research interests are in psychometrics and methodology.

Katariina Salmela-Aro, Professor, Educational Sciences, University of Helsinki, Finland. Visiting Professor, Institute of Education, University College London and School of Education, Michigan State University. Director of several ongoing longitudinal studies such as FinEdu, Gaps and PIRE. Her key interests are motivation, well-being, educational transitions and related interventions. 